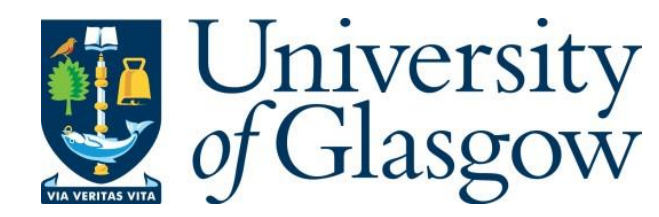

Thompson, D. L., Ovenden, T. S., Pennycott, T. and Nager, R. G. (2020) The prevalence and source of plastic incorporated into nests of five seabird species on a small offshore island. Marine Pollution Bulletin, 154, 111076.

There may be differences between this version and the published version. You are advised to consult the publisher's version if you wish to cite from it.

$\underline{\text { http://eprints.gla.ac.uk/227294/ }}$

Deposited on: 2 February 2021

Enlighten - Research publications by members of the University of Glasgow http://eprints.gla.ac.uk 


\title{
The prevalence and source of plastic incorporated into nests of five seabird species on a small offshore island.
}

Running title: Prevalence and source of plastic incorporated in seabird nests.

Danielle L Thompson ${ }^{1 *}$ (OrcID: 0000-0003-2450-0459), Thomas S Ovenden ${ }^{2}$ (OrcID: 0000-0002-69571333), Tom Pennycott ${ }^{3}$, Ruedi G Nager ${ }^{1}$ (OrcID: 0000-0003-1129-5724)

${ }^{1}$ Graham Kerr Building, IBAHCM, University of Glasgow, Glasgow, G12 8QQ, UK

2 Biological and Environmental Sciences, School of Natural Sciences, University of Stirling, Stirling, FK9 4LA, UK

3. Browncarrick Drive, Ayr, KA7 4JA

*Corresponding author: dthompson5@hotmail.co.uk

\begin{abstract}
There is little evidence documenting the prevalence of plastic nest incorporation for different seabird species and populations, and even less detailing the source of such debris as nesting material. This study presents a baseline dataset on the presence of plastic in the nests of five seabird species on Lady Isle, Scotland using a novel and repeatable methodology for quantifying plastic incorporated into nests. Plastic was found in $24.5 \%$ to $80 \%$ of nests of all species. We analysed pellets of regurgitated material and the spatial distribution of herring gull nests containing plastic in the context of the tide and nesting habitat. Differences in the types of plastic found in pellets and nests suggests that plastic incorporated into herring gull nests was not derived at foraging sites and likely collected from the local environment. Targeted beach cleans before the breeding season could help minimise the quantity of plastic available to herring gulls.
\end{abstract}

Key words: plastic ingestion; nest-building; North Atlantic; marine debris; plastic pollution; litter. 


\section{INTRODUCTION}

Plastic debris was first recognised as a serious form of marine pollution in the 1990s (Laist, 1997). Production of plastic continues to increase (PlasticsEurope, 2014) and inadequate waste management means that vast quantities of plastic end up in the environment (Bergmann et al., 2015). Due to their very nature, plastics can remain in the environment for centuries (Li et al., 2016), posing a threat to wildlife (Elliott and Elliott, 2013; Rochman et al., 2013; Teuten et al., 2009). In the marine environment, over 663 species, including reptiles, mammals and birds, are reported to be affected by plastic debris, and it may be one of the key factors threatening biodiversity loss (Secretariat of the Convention on Biological Diversity, 2012). In order to assess the risk of marine plastic pollution we need to know over what spatial scale and from what sources marine wildlife obtain plastic debris, but this is often unknown (Provencher et al., 2019).

Across the world's oceans, seabirds are increasingly likely to interact with plastic debris through ingestion, entanglement or nest incorporation (e.g. Battisti et al., 2019; O'Hanlon et al., 2017a, 2019; Ryan, 2018; Wilcox et al., 2015). Compared to plastic ingestion, incorporation of marine debris into nests has thus far received less attention (O'Hanlon et al., 2017a) despite the fact that it has been found in a number of seabird species (albatrosses: Nel and Nel, 1999; boobies and gannets: Bond et al., 2012; Grant et al., 2018; Lavers et al., 2013; Norman et al., 1995; O'Hanlon et al., 2019; Verlis et al., 2014; Votier et al., 2011; cormorants: Podolsky and Kress, 1989; gulls and terns: Battisti 2020; Clemens and Hartwig, 1993; Hartwig et al., 2007; de Souza Petersen et al., 2016; Witteveen et al., 2017). Some studies have found plastic debris in nests to be common, for instance, $80 \%$ of nests in a Northern gannet (Morus bassanus) colony in Wales, UK, contained marine debris with direct evidence of entanglement killing birds every year (Votier et al., 2011), while other studies found that nest incorporation of plastic in a colony of black-legged kittiwakes (Rissa tridactyla) increased by 11 $\%$ in 13 years (Hartwig et al., 2007). The majority of observations report that commonly incorporated debris is in the form of rope and fishing net (Clemens and Hartwig, 1993; Hartwig et al., 2007; Schneider, 1993; Secretariat of the Convention on Biological Diversity, 2012; Votier et al., 2011), however Witteveen et al (2017) also reported dietary-related items such as bags and food wrappers in nests of kelp gulls (Larus dominicanus). As the nest is a key functional structure linked to reproductive success (Mainwaring et al., 2014), any structural alterations that compromise the functional performance of a nest (e.g. its thermal properties, structural integrity, drainage, camouflage), such as through the incorporation of plastic debris, may subsequently impact fitnessrelated traits of offspring, with the potential for population-level consequences.

There is currently very little knowledge on whether incorporation of marine plastic debris into nests is affected only by plastic pollution in the area immediately surrounding the nest, or over a larger, and potentially the entire, home range of a population. The distribution and accumulation of debris in the coastal and marine environment is affected by proximity to urban areas (Leite et al., 2014), proximity to rivers (Sadri and Thompson, 2014), tidal currents and prevailing winds (Eriksson et al., 2013). There are mixed reports on the source of and reasoning for plastic incorporation into nests, suggesting variation between species and localities (e.g. Battisti, 2020; Lavers et al., 2013; Sergio et al., 2011; Votier et al., 2011; Witteveen et al., 2017). Birds may collect man-made debris deliberately for nest building, possibly actively as decorative functions (Sergio et al., 2011) or accidentally due to the similarity of at least some marine debris to suitable natural nesting material (Votier et al., 2011). 
The availability of natural nesting material and marine debris at the scale over which nest material is collected can also influence plastic incorporation into nests. For instance, in brown boobies (Sula leucogaster) nest incorporation of plastic was more likely to occur at breeding sites with little natural vegetation available to build nests from (Lavers et al., 2013). Conversely, other species such as kelp gulls and yellow-legged gulls (L. michahellis) might not obtain the plastic debris found in their nests while gathering nesting material; instead it may be derived from debris picked up while foraging and the indigestible material then regurgitated at the nest (Battisti, 2020; Witteveen et al., 2017). In this latter case we would not expect a spatial pattern of plastic incorporation into nests. To gain an insight into the source of plastic debris that becomes incorporated into nests, an exploration of the spatial pattern of nests that incorporate plastic and how it is related to local geographic features, the relationship between plastic incorporated into the nest and plastic ingestion of the breeding pair is needed.

Gulls are one of the seabird taxa that most heavily interact with plastic debris (Basto et al., 2019), but data about plastic presence in their nests is still scarce. Here we studied the presence and spatial distribution of plastic debris in the nests of European herring gulls (L. argentatus), lesser blackbacked gulls (L. fuscus), great black-backed gulls (L. marinus), and compared them with European shags (Phalacrocorax aristotelis) and great cormorants ( $P$. carbo) nesting at the same site. To determine the possible driver(s) of plastic in nests, we focused on herring gulls.

Herring gulls are generalists foraging on marine, terrestrial and anthropogenic resources, although they are increasingly exploiting the latter (Kubetzki and Garthe, 2003). Indigestible food items are regurgitated providing a non-invasive method for analysing both diet (Barrett et al., 2007) and plastic ingestion (Acampora et al., 2017; Álvarez et al., 2018). We thus investigated how incorporated plastic in nests is related to plastic ingested by the pair attending the nest site during the incubation stage. Herring gulls are typically ground nesting, with both males and females collecting material for the nest independently from each other, usually from the surroundings of the nest site (Tinbergen, 1953). We also studied the relationship between plastic presence in herring gull nests and both the substrate on which the nest was constructed, either on the rocky shore or vegetated interior of the island, and the location of the nest in relation to the outgoing tide. As the study site is an uninhabited island, any plastic occurring on the island will likely be washed up on the rocky shore facing the outgoing tide where plastic debris from the nearby mainland can be deposited.

If gulls, as suggested by Witteveen et al. (2017) and Battisti (2020), mainly collect plastic debris while foraging then we would expect a positive relationship between plastic debris in the nests and the diet, and those nests with plastic incorporated would be randomly distributed between different nesting habitats and in proximity to the outgoing tide. If the local nest surroundings are the main source of plastic in the nest then we will expect to find a higher prevalence of debris in nests located along the rocky shore than those in the vegetated interior, and in the northern half of the island where plastic debris is more likely deposited by the outgoing tide coming from the mainland. By providing new insights into the sources of plastic incorporated into seabird nests and developing our understanding of the origin of plastic debris in the nests of seabirds, this study can help inform mitigation activities and effectively target limited resources and conservation funds. 


\section{METHODS}

\section{Study site}

We studied plastic incorporation in seabird nests on Lady Isle, a small island $5.6 \mathrm{~km}$ off the coast of Ayrshire in the Firth of Clyde, Scotland (Lat: 55.526004; Long: -4.7327647) (Error! Reference source not found.). The island is uninhabited and is approximately 4.4 ha in area and has a maximum elevation of $6 \mathrm{~m}$. Characterised by a rocky coastline with peaty soils, the vegetation consists of common nettle (Urtica dioica), curled dock (Rumex crispus), spear thistle (Cirsium vulgare), bluebells (Hyacinthoides non-scripta) and annual meadow grass (Poa annua) (Grant et al., 2013). Originally afforded protection as a nature reserve due to its roseate tern (Sterna dougallii) colony in the 1950s, Lady Isle is now an important roost and breeding site for European herring gulls (Larus argentatus), lesser black-backed gulls (L. fuscus), great black-backed gulls (L. marinus), European shags (Phalacrocorax aristotelis), great cormorants (P. carbo) and common eiders (Somateria mollissima) (Grant et al., 2013).

\section{Data collection}

Lady Isle was surveyed on 14 and 18 May 2018 for all nesting seabird species. For all species, each nest found ( $n=1597)$ was given a unique ID and the following data were collected: species name, GPS location, and presence or absence of plastic. In addition, a randomly selected sample of herring gull nests spread out throughout the colony containing plastic were also photographed $(n=145)$ from approximately one metre above the nest using a Canon EOS 500D digital camera. If fresh regurgitated pellets were present within the vicinity of a herring gull nest, i.e. in the nest or around the nest rim, these were collected and given a reference ID to match it to the corresponding nest (n $=57$ pellets from 30 nests). Pellets were not collected if there was any uncertainty with regards to the source nest.

\section{Nest analysis}

To assess the quantity of plastic in those herring gull nests which were photographed, CPCe software (Kohler and Gill, 2006) was used to carry out systematic random point sampling. To the authors' knowledge, this study is the first to use the software and such a methodology to assess the quantity of plastic debris in seabird nests. The sampling method was chosen to quantify nest material to ensure coverage of the whole nest. Using the software, a square border was drawn along the outside edge of the main nest to incorporate the nest cup, where plastic is likely to have any influence on nest quality, and some of the outer edge, giving a more accurate image of what material the nest has been constructed with (Fig. 2). Following the methodology used by Dumas et al. (2009) and using the CPCe software, the space within the drawn border was converted to a $3 \times 3$ grid, and 11 random points in each grid square were generated, producing 99 random points per nest. Material underlying each of the points was categorised as either: natural, plastic, man-made (non-plastic), egg or other. Natural nest material was further categorised as having marine or terrestrial origin, or a mix of the two. Plastic material was further categorised by colour and type following the methodology outlined by Provencher et al. (2017), and the proportion of nests containing each of these categories determined.

Two replications of the above methodology were carried out for each nest, using a new selection of random points for each replicate. For each replication of 99 points, the quantity of points which were egg and rock were subtracted from the total, as these are not gathered nest materials and may skew the data. The percentage of plastic making up the remainder was calculated, and the quantities of plastic found in the two replicates for the same nest showed a strong positive correlation $\left(r_{143}=\right.$ 
$0.8, p<0.001)$ using Pearson's PMCC. The percentage of plastic recorded for each nest across both replications was therefore averaged to give each unique nest a single mean value of plastic.

The percentage of each plastic type and colour found in each replicate was calculated. To avoid duplication and to account for variation across both replicates, these figures were combined to produce a mean percentage for each category.

\section{Pellet analysis}

A mean of 1.9 ( $S E=0.24$, range 1-6) pellets per nest were collected from the immediate vicinity of 30 herring gull nests. These were stored in a freezer until dissection offsite. Pellets were defrosted, softened in water for two hours, then mechanically teased apart and examined grossly under a binocular dissecting microscope (magnification range 7-45, Brunel Microscopes Ltd, Chippenham, United Kingdom). The main component(s) were identified, including the type and colour of any plastic debris. Where several pellets were collected from the same nest site, the proportion of pellets containing plastic was averaged across all pellets from that nest site.

\section{Habitat stratification}

As data collection was carried out in 2018, Multi-Spectral Sentinel 2 data was available to delineate the boundary between different habitat types (rocky shore or vegetation), and subsequently allocate this habitat type to each nest. Sentinel 2 data was selected due to its superior spatial resolution $(10 \mathrm{~m})$ to other available products such as Landsat data $(30 \mathrm{~m})$. Sentinel 2 image data from $28^{\text {th }}$ May 2018 was selected based on its proximity to the date of data collection whilst also minimising cloud cover and thus increasing image clarity. The Normalized Difference Vegetation Index (NDVI) is an index commonly used to differentiate green vegetation from other surrounding material in remote sensing data. We used ArcGIS 10.3.1 (Environmental Systems Research Institute (ESRI), 2018) to calculate NDVI for Lady Isle using this Sentinel 2 imagery with a threshold value of NDVI $\geq 0.45$ to indicate vegetated areas. The effectiveness of this NDVI threshold in delineating the vegetation boundary was visually cross checked against the Sentinel 2 aerial imagery.

To account for the effect of the outgoing tide that is roughly in a north-south direction in the area of Lady Isle (Sabatino et al., 2016), the island was bisected accordingly by a horizontal line, separating nests on the northern half from those on the southern half, using QGIS.

\section{Statistical analysis}

We related the proportion of pellets with plastic and the quantity of plastic in the nests using a Spearman rank correlation $r_{s}$ owing to the non-normal distribution of the data $(n=30)$; this allowed us to test whether herring gulls which had plastic in their nests were more likely to have a greater amount of plastic in their pellets than those which did not have plastic in their nest. A G-test was used to compare the plastic type and colour between nests and pellets. Due to the small sample size, the data was grouped and analysed together as opposed to testing individual nests and their associated pellets. Means \pm standard error are shown throughout.

A G-test was used to compare the percentage of plastic in nests between species, and $95 \%$ confidence intervals were calculated using the Jeffreys interval ( $R$ package binom, Dorai-Raj, 2014).

QGIS (QGIS Development Team, 2018) was used to plot the locations of all herring gulls nests. A 5m buffer was added to the perimeter of the island to account for any small inaccuracies in GPS derived nest locations, and any nests outside of this buffer $(n=16)$ were removed from the spatial analysis. 
Using a binomial model with presence or absence of plastic debris in the nest as response variable and with both the NDVI habitat classification and location of the nest in relation to the outgoing tide as the explanatory variables using the Ime4 package, we tested whether herring gull nests were more likely to contain plastic if they were situated in the grassy interior of the island or on the rocky perimeter, and if they were more or less exposed to the outgoing tide. All statistical analysis was performed in R ( $R$ Core Team, 2016).

\section{RESULTS}

In total we surveyed 1,597 nests and recorded plastic in 625 of these. There were statistically significant differences in percentage of nests with plastic incorporated between species ( $G=160.85$, $\mathrm{df}=4, \mathrm{p}<0.001$ ) with shags showing the highest proportion of nests containing plastic and cormorants and lesser black-backed gulls showing the lowest levels of plastic incorporation (Fig. 3).

Among all 1,022 herring gull nests, $35.6 \%$ showed evidence of plastic incorporation. For a subset of 145 nests containing plastic we examined nest material, and quantity, type and colour of incorporated plastic in more detail using nest photographs. Every herring gull nest photographed was constructed of mainly natural material of terrestrial origin. A small proportion $(10.34 \%, n=15)$ also contained some marine material (seaweed). There were no nests which were constructed solely from marine material. On average $0.44 \pm 0.003 \%$ (range $0-24.24 \%$ ) of the nest surface was made of plastic debris. Of the plastic found in these nests, $95.05 \pm 1.1 \%$ was sheet plastic, $4.05 \pm 0.4 \%$ was threadlike and a very small amount was hard fragment plastic $(0.91 \pm 0.71 \%)$. Most plastic $(86.84 \pm$ $3.41 \%$ ) was off-white/clear in colour, $5.67 \pm 1.61 \%$ was blue-purple, $5.16 \pm 0.7 \%$ was black, very small amounts of plastic were found to be red-pink ( $1.42 \pm 0.2 \%)$, grey-silver ( $1.01 \pm 0.51 \%$ ), yellow $(0.61 \pm 0.31 \%)$ and green $(0.1 \pm 0.1 \%)$, and none were orange-brown.

Of the herring gull nests where we examined plastic ingestion through pellet analyses, pellets from 17 out of 30 nests ( 22 out of 57 pellets) contained plastic. They contained either threadlike, sheet and/or hard fragments of plastics in a range of colours (Table 1). The pellets also contained other anthropogenic debris such as aluminium foil, paper and glass, with many individual items measuring less than $1 \mathrm{~cm}^{2}$. The composition of types of plastics found in herring gull nests from which we also analysed pellets was significantly different from that in their pellets $(G=20.16, d f=4, p<0.001)$, but this was not the case for colours of plastic ( $G=8.48, d f=7, p=0.293$; Table 1). Critically, plastic occurrence in herring gull pellets and nests was not correlated (Fig. 4).

Herring gull nests located in the north of the island were significantly more likely to have incorporated plastic in their nests. While $42.3 \%$ of herring gull nests in the northern half contained plastic, significantly fewer nests ( $32.1 \%$ of nests) in the southern part had plastic incorporated into their nests (Table 2 and Fig. 5). There was no difference in presence of plastic in nests between the two substrates.

\section{DISCUSSION}

This study has produced novel insights into the source of plastic incorporated into the nests of herring gulls, suggesting plastic in nests and diet likely comes from different sources and therefore, a 'one size fits all solution' i.e. a beach clean, might not be sufficient to address the whole plastic problem as it may only help with nest plastic, not plastic ingestion. We present here a repeatable 
methodology for assessing the quantity of plastic in nests which can be applied to ground-nesting bird species globally. We have also gathered a baseline dataset for five seabird species on Lady Isle, none of which have been assessed in the literature until now with regards to nest incorporation of plastic. Plastic incorporation into nests differed between species. Thus, this research highlights the need for greater ecological understanding of study species if we are to begin to understand the source and potential impact of plastic on seabirds and mitigate it.

The occurrence of incorporated plastic ranged from 24.5 to $80 \%$ of nests, depending on species. The range of proportion of nests with plastic at our site is similar to what has been observed elsewhere, with occurrence ranging from 4 - 80\% dependent on colony and species (Battisti, 2020; Hartwig et al., 2007; Tavares et al., 2016; Votier et al., 2011; Witteveen et al., 2017). Such variation between species might be explained by their differing breeding ecologies. Unlike gulls, shags reuse the same nests over multiple years (Snow, 1960). Plastic could therefore accumulate in the nests over many years which may explain why we observed a higher prevalence of plastic incorporated in shag nests than the nests of other species.

\section{Assessment of nest incorporation of plastic}

We developed a simple and quick analysis tool that utilises easily collected image data to assess plastic nest incorporation by quantifying the presence of visible plastic debris on or in the nest. Crucially, our approach provides a repeatable method that also enables us to begin to understand the differential impact of alternative types of plastic waste. For future use, the delineation of the nest boundary could be done more objectively, for instance using a frame of a standardised size, so it is clearer whether plastic in the peripheral areas of the nest should be included, although the frequency of such occurrences was very low (pers. obs). It is possible that the small size of the plastic found within pellets means that detection of plastic from degraded pellets was less likely within nests, but this also reaffirms that the larger plastic items found in the nests were unlikely to be sourced from regurgitated pellets.

Some of the advantages and disadvantages of using regurgitated pellets to assess the diet of seabirds were discussed by Barrett et al. (2007). In the current study, pellets containing compacted debris from landfill sites may degrade more slowly than more friable pellets such as those consisting of cereal chaff or the remains of fish or crustaceans, potentially artificially increasing the proportion of pellets in which plastic was found. This potential bias was overcome by expressing the results as the percentage of nests in which plastic was found in associated pellets, rather than the percentage of pellets which were found to contain plastic.

\section{Plastic type and colour incorporated into nests}

In the present study, the majority of plastic incorporated into herring gull nests was sheet plastic and off-white/clear in colour. The colour of plastics found in the herring gull nests was similar to that found in other seabird nests (e.g., Clemens and Hartwig, 1993; Grant et al., 2018; Hartwig et al., 2007), and sheet plastic mostly from packaging was also the most common plastic debris found in kelp gull nests (Witteveen et al., 2017). As all nests contained terrestrial nest material that was pale in colour, this similarly coloured plastic was not conspicuous, suggesting it could have been selected due to its similarity in colour to natural material. To test whether this were the case, future studies should be expected to find a bias towards black plastic incorporated in nests constructed primarily of marine material (black in colour). In contrast, sheet plastic found to be integrated with natural nesting material does not obviously resemble the shape of terrestrial vegetation - the main nesting material in our herring gull population - suggesting it is unlikely that plastic debris incorporated into nests was erroneously picked up as the natural nesting material. It is however worth noting that 
pale-coloured threadlike plastic is the most likely debris to be missed in the photographs and should be accounted for in future studies. Further research could focus on addressing behavioural responses to plastic in the environment i.e. preferential choice. by using more complex indices to assess plastic diversity found in the nest.

Larger plastic items were often found on the periphery of herring gull nests away from the eggs and outside of the survey boundary. This might imply a preference for natural material for the incubation of eggs. On the other hand, larger pieces of debris may be less easily woven and incorporated into a nest, so may be more susceptible to displacement by wind and animal movement.

In herring gull nests, the majority of plastic items that were identified as sheet plastic appeared to be packaging or cling film-type debris. No large rope or netting was identified in nests, and thus the debris found in the gull nests appeared to be from consumer waste. These findings contrast with other observations which found a high proportion of threadlike debris (Hartwig et al., 2007; Schneider, 1993; Votier et al., 2011) possibly from commercial and recreational fishing. However, higher frequencies of threadlike debris were found in the nests of shags on Lady Isle (pers. obs.). This could suggest that different species and colonies may be affected by different plastic sources depending on nest building behaviour and/or due to the locality of the colony, which will be affected by local industry, tides and currents (see below).

\section{Origin of plastic debris found in nests}

We aimed to identify whether the source of plastic in the nests of herring gulls likely came from plastic ingested whilst foraging then regurgitated in pellets back at the nesting site, or whether it was more likely to have been collected from the local environment. Witteveen et al. (2017) suggested, based on comparisons between colonies which differed in their distance to the nearest landfill, that the likelihood of plastic debris in gull nests increased with decreasing distance to landfills. The birds may not have deliberately collected debris for nest building but instead may have regurgitated debris into their nests which they accidentally ingested while foraging at landfills, making it a potential major source of plastic in gull nests (Battisti, 2020; Witteveen et al., 2017). Previous research found that the majority of the identified diet items on Lady Isle were from terrestrial foraging sites, including landfills, suggesting that the birds mainly forage on the mainland and less frequently in the surrounding sea (O'Hanlon et al., 2017b). Therefore, accidental ingestion of debris when foraging on human waste is potentially a source of plastic debris in their nests, particularly as the incorporated debris on Lady Isle was indicative of consumer waste. However, if accidentally ingested plastic is the main source of plastic in nests then we would have expected a positive relationship between the proportion of plastic debris in the nest and diet within colonies. We did not, however, find such a relationship in herring gulls. Moreover, we also would have expected a similar composition of types and colours of plastic debris in nests and pellets. In contrast, we found a difference in the composition of types of plastic between nests and pellets, although not for colours of plastics.

Only a small number of the nests where pellets were found also contained plastic and future studies should aim to further verify if there is a relationship between plastic ingestion and nest incorporation. That we have not found the predicted positive relationship between plastic in the nest and diet may be due to the sample size of the number of pellets examined per nest. However, like many seabirds, gulls show a relatively high consistency in their diet, at least over the short term (Ceia and Ramos, 2015), so that even a small number of pellets should be reasonably representative for their diet at the time. The presence of other anthropogenic materials, suggestive of landfill, within the analysed pellets further suggests that the herring gulls are foraging and collecting nest 
material from different sources. It could also be that the diet preferences differ between the male and the female, and the small number of pellets might be biased towards one of the two birds whereas the other bird may have contributed more to the nest. Alternatively, gulls could collect plastic debris, either deliberately or accidentally, for nest building. Witteveen et al. (2017) found that nests in colonies presumed to have more ready access to stranded plastic debris were more likely to contain plastic debris in the nests, in which case, it was less likely in their study that the debris came from regurgitating accidentally ingested material.

Plastic incorporation in nests on Lady Isle was not correlated with a particular substrate, therefore our results suggest that plastic incorporation in herring gull nests was likely linked to the availability of plastic rather than an absence of natural nesting material. There was a relationship between the location of nests on the island in relation to the outgoing tide. This suggests that the plastic incorporated in nests may have originated from the mainland and been transported to the island via the outgoing tide. It also suggests support for previous findings that gulls most likely collect nest material in the area surrounding their nests. However, the presence of plastic in the south of the island implies that the range over which they collect nest material may be at least as large as the island or additional factors, such as the wind, may also influence the quantity and distribution of plastic on the island, and consequently it's availability to nest-building herring gulls. Opportunistic stealing of nest material from unattended neighbouring nests (Verner, 1961) may also contribute to the distribution of nests containing plastic debris.

\section{Conclusion}

Plastic debris was prevalent in all five species of seabird nesting on a small offshore island and this study provides a baseline dataset on the frequency of nests having incorporated plastic in these species on Lady Isle. Looking in more detail at the most numerous species, the herring gull, suggested that plastic debris in their nests most likely originated from consumer waste that may have washed-up onto the nesting territory from a mainland source, and less likely from accidentally ingested debris that is then regurgitated at the nest site. It could be that the origin of plastic in nests may vary between species and colonies within species (see also Grant et al., 2018). Our finding suggests that herring gulls use mostly locally available debris rather than re-distributing plastic debris across the landscape as it would have been the case if nest plastic would have been mainly derived from ingested plastic. We recommend behavioural observations of breeding herring gulls during the nest building phase to confirm that the birds are more likely to collect nesting material local to the nest site (Tinbergen, 1953) rather than from elsewhere, and to determine how far this range extends. There was a distinct lack of literature on the nest-building behaviour of herring gulls leading us to believe that this is an understudied area in the behavioural ecology of this species relevant to understanding the impact of plastic litter on this species. It would also be of interest to conduct beach litter surveys around colonies and perform analyses at several spatial scales to identify at what spatial scale there is a relationship between plastic within nests and plastic in the local nesting environment.

It remains to be studied what impact nest incorporation of plastic debris has on populations, whether direct and/or indirect. While threadlike plastic debris is known to cause mortality through entanglement (Votier et al. 2011), sheet plastic (the predominant plastic type found in the nests of herring gulls on Lady Isle) is unlikely to cause entanglement mortality (Ryan, 2018). However, the structure and properties of sheet plastic could, for example, alter the thermal and drainage properties of the nest which could impact on reproductive success. Further research is needed to identify whether or not plastic presence in nests has an impact on seabird populations and if so, by what mechanism and to what extent. It is critically important that we begin to gather baseline data 
and initiate long-term monitoring programmes to assess the prevalence and impact of plastic incorporation into nests, particularly in seabird species that are exposed to large quantities of marine plastic. Plastic debris is increasing but so is public awareness, providing an opportunity to assess the outcome of conservation and waste management measures as a result of public pressure and targeted attention. Incorporating such data collection into existing monitoring programmes worldwide should be considered in future years. However, it is important that a standardised methodology is created and adhered to, to allow for spatial and temporal comparisons. By developing a sampling methodology, this study is an important first step in understanding the sources and impacts of plastic debris on seabird populations, creating baseline data for monitoring spatial and temporal changes, and for targeted conservation management actions. Long-term monitoring of plastic occurrence within seabird colonies should be conducted to allow us to identify changes over time, and to determine the efficacy of waste reduction measures.

\section{Acknowledgements}

The authors wish to thank Dave Grant, Hayley Douglas and Agnes Olin for help in the field, Nina O'Hanlon and Agnes Olin for comments on a previous draft of the manuscript, Matt Page for help with assessing tidal flow directions in the study area, and Maria Bogdanova for the discussion of analyses. We are very grateful to the editor and to two anonymous reviewers for their positive and constructive comments which have ultimately strengthened this manuscript.

\section{Declarations of Interest}

None.

This research did not receive any specific grant from funding agencies in the public, commercial, or not-for-profit sectors.

\section{REFERENCES}

Acampora, H., Berrow, S., Newton, S., O'Connor, I., 2017. Presence of plastic litter in pellets from great cormorant (Phalacrocorax carbo) in Ireland. Marine Pollution Bulletin 117, 512-514. https://doi.org/10.1016/j.marpolbul.2017.02.015

Álvarez, G., Barros, Á., Velando, A., 2018. The use of European shag pellets as indicators of microplastic fibers in the marine environment. Marine Pollution Bulletin 137, 444-448. https://doi.org/10.1016/j.marpolbul.2018.10.050

Barrett, R.T., Camphuysen, K. (C J.), Anker-Nilssen, T., Chardine, J.W., Furness, R.W., Garthe, S., Hüppop, O., Leopold, M.F., Montevecchi, W.A., Veit, R.R., 2007. Diet studies of seabirds: a review and recommendations. ICES J Mar Sci 64, 1675-1691. https://doi.org/10.1093/icesjms/fsm152

Basto, M.N., Nicastro, K.R., Tavares, A.I., McQuaid, C.D., Casero, M., Azevedo, F., Zardi, G.I., 2019. Plastic ingestion in aquatic birds in Portugal. Marine Pollution Bulletin 138, 19-24. https://doi.org/10.1016/j.marpolbul.2018.11.024

Battisti, C., 2020. Heterogeneous composition of anthropogenic litter recorded in nests of Yellowlegged gull (Larus michahellis) from a small Mediterranean island. Marine Pollution Bulletin 150, 110682. https://doi.org/10.1016/j.marpolbul.2019.110682

Battisti, C., Staffieri, E., Poeta, G., Sorace, A., Luiselli, L., Amori, G., 2019. Interactions between anthropogenic litter and birds: A global review with a 'black-list' of species. Marine Pollution Bulletin 138, 93-114. https://doi.org/10.1016/j.marpolbul.2018.11.017

Bergmann, M., Gutow, L., Klages, M. (Eds.), 2015. Marine Anthropogenic Litter. Springer International Publishing, Cham Heidelberg New York Dordrecht London.

Bond, A.L., Montevecchi, W.A., Guse, N., Regular, P.M., Garthe, S., Rail, J.-F., 2012. Prevalence and composition of fishing gear debris in the nests of northern gannets (Morus bassanus) are 
related to fishing effort. Marine Pollution Bulletin 64, 907-911.

https://doi.org/10.1016/j.marpolbul.2012.03.011

Ceia, F.R., Ramos, J.A., 2015. Individual specialization in the foraging and feeding strategies of seabirds: a review. Mar Biol 162, 1923-1938. https://doi.org/10.1007/s00227-015-2735-4

Clemens, T., Hartwig, E., 1993. Müll als nistmaterial von dreizehenmöwen (Rissa tridactyla)untersuchung einer brutkolonie an der Jammerbucht, Dänemark. Seevögel 14, 6-7.

de Souza Petersen, E., Krüger, L., Dezevieski, A., Petry, M., Montone, R.C., 2016. Incidence of plastic debris in sooty tern nests: A preliminary study on Trindade Island, a remote area of Brazil. Marine Pollution Bulletin 105, 373-376. https://doi.org/10.1016/j.marpolbul.2016.02.036

Dorai-Raj, S., 2014. binom: Binomial Confidence Intervals for Several Parameterizations.

Dumas, P., Bertaud, A., Peignon, C., Léopold, M., Pelletier, D., 2009. A "quick and clean" photographic method for the description of coral reef habitats. Journal of Experimental Marine Biology and Ecology 368, 161-168. https://doi.org/10.1016/j.jembe.2008.10.002

Elliott, J.E., Elliott, K.H., 2013. Tracking Marine Pollution. Science 340, 556-558. https://doi.org/10.1126/science.1235197

Environmental Systems Research Institute (ESRI), 2018. ArcGIS. Redlands, CA.

Eriksson, C., Burton, H., Fitch, S., Schulz, M., van den Hoff, J., 2013. Daily accumulation rates of marine debris on sub-Antarctic island beaches. Marine Pollution Bulletin 66, 199-208. https://doi.org/10.1016/j.marpolbul.2012.08.026

Grant, D., Robertson, D., Nager, R., McCracken, D., 2013. The status of breeding gulls on Lady Isle, Ayrshire, 2012. Scottish Birds 33, 298-307.

Grant, M.L., Lavers, J.L., Stuckenbrock, S., Sharp, P.B., Bond, A.L., 2018. The use of anthropogenic marine debris as a nesting material by brown boobies (Sula leucogaster). Marine Pollution Bulletin 137, 96-103. https://doi.org/10.1016/j.marpolbul.2018.10.016

Hartwig, E., Clemens, T., Heckroth, M., 2007. Plastic debris as nesting material in a kittiwake- (Rissa tridactyla)-colony at the Jammerbugt, Northwest Denmark. Marine Pollution Bulletin 54, 595-597. https://doi.org/10.1016/j.marpolbul.2007.01.027

Kohler, K.E., Gill, S.M., 2006. Coral Point Count with Excel extensions (CPCe): A Visual Basic program for the determination of coral and substrate coverage using random point count methodology. Computers \& Geosciences 32, 1259-1269. https://doi.org/10.1016/j.cageo.2005.11.009

Kubetzki, U., Garthe, S., 2003. Distribution, diet and habitat selection by four sympatrically breeding gull species in the south-eastern North Sea. Marine Biology 143, 199-207. https://doi.org/10.1007/s00227-003-1036-5

Laist, D.W., 1997. Impacts of Marine Debris: Entanglement of Marine Life in Marine Debris Including a Comprehensive List of Species with Entanglement and Ingestion Records, in: Marine Debris, Springer Series on Environmental Management. Springer, New York, NY, pp. 99-139. https://doi.org/10.1007/978-1-4613-8486-1_10

Lavers, J.L., Hodgson, J.C., Clarke, R.H., 2013. Prevalence and composition of marine debris in brown booby (Sula leucogaster) nests at Ashmore Reef. Marine Pollution Bulletin 77, 320-324. https://doi.org/10.1016/j.marpolbul.2013.09.026

Leite, A.S., Santos, L.L., Costa, Y., Hatje, V., 2014. Influence of proximity to an urban center in the pattern of contamination by marine debris. Marine Pollution Bulletin 81, 242-247. https://doi.org/10.1016/j.marpolbul.2014.01.032

Li, W.C., Tse, H.F., Fok, L., 2016. Plastic waste in the marine environment: A review of sources, occurrence and effects. Science of The Total Environment 566-567, 333-349. https://doi.org/10.1016/j.scitotenv.2016.05.084

Mainwaring, M.C., Hartley, I.R., Lambrechts, M.M., Deeming, D.C., 2014. The design and function of birds' nests. Ecology and Evolution 4, 3909-3928. https://doi.org/10.1002/ece3.1054 
Nel, D.C., Nel, J.L., 1999. Marine debris and fishing gear associated with seabirds at sub-Antarctic Marion Island 1996/97 and 1997/98: in relation to longline fishing activity. CCAMLR Science 6, 85-96.

Norman, F.I., Menkhorst, P.W., Hurley, V.G., 1995. Plastics in nests of Australasian gannets Morus serrator in Victoria, Australia. Emu - Austral Ornithology 95, 129-133. https://doi.org/10.1071/MU9950129

O'Hanlon, N.J., Bond, A.L., Lavers, J.L., Masden, E.A., James, N.A., 2019. Monitoring nest incorporation of anthropogenic debris by Northern Gannets across their range. Environmental Pollution 255, 113152. https://doi.org/10.1016/j.envpol.2019.113152

O'Hanlon, N.J., James, N.A., Masden, E.A., Bond, A.L., 2017a. Seabirds and marine plastic debris in the northeastern Atlantic: A synthesis and recommendations for monitoring and research. Environmental Pollution. https://doi.org/10.1016/j.envpol.2017.08.101

O'Hanlon, N.J., McGill, R.A.R., Nager, R.G., 2017b. Increased use of intertidal resources benefits breeding success in a generalist gull species. Marine Ecology Progress Series 574, 193-210. https://doi.org/doi:10.3354/meps12189

PlasticsEurope, 2014. Plastics - The Facts 2014: An Analysis of European Plastics Production. Demand and Waste Data, Brussels.

Podolsky, R.H., Kress, S.W., 1989. Plastic debris incorporated into double-crested cormorant nests in the Gulf of Maine (Desperdicios plásticos incorporados en nidos de Phalacrocorax auritus estudiados en el Golfo de Maine). Journal of Field Ornithology 60, 248-250.

Provencher, J.F., Ammendolia, J., Rochman, C.M., Mallory, M.L., 2019. Assessing plastic debris in aquatic food webs: what we know and don't know about uptake and trophic transfer. Environmental Reviews 27, 304-317.

Provencher, J.F., Bond, A.L., Avery-Gomm, S., Borrelle, S.B., Rebolledo, E.L.B., Hammer, S., Kühn, S., Lavers, J.L., Mallory, M.L., Trevail, A., Franeker, J.A. van, 2017. Quantifying ingested debris in marine megafauna: a review and recommendations for standardization. Anal. Methods 9 , 1454-1469. https://doi.org/10.1039/C6AY02419J

QGIS Development Team, 2018. QGIS Geographic Information System. Open Source Geospatial Foundation Project.

R Core Team, 2016. R: A language and environment for statistical computing. R Foundation for Statistical Computing, Vienna, Austria.

Rochman, C.M., Hoh, E., Kurobe, T., Teh, S.J., 2013. Ingested plastic transfers hazardous chemicals to fish and induces hepatic stress. Scientific Reports 3, 3263. https://doi.org/10.1038/srep03263

Ryan, P.G., 2018. Entanglement of birds in plastics and other synthetic materials. Marine Pollution Bulletin 135, 159-164. https://doi.org/10.1016/j.marpolbul.2018.06.057

Sabatino, A.D., Murray, R.B., Hills, A., Speirs, D.C., Heath, M.R., 2016. Modelling sea level surges in the Firth of Clyde, a fjordic embayment in south-west Scotland. Natural Hazards 84, 16011623.

Sadri, S.S., Thompson, R.C., 2014. On the quantity and composition of floating plastic debris entering and leaving the Tamar Estuary, Southwest England. Marine Pollution Bulletin 81, 55-60. https://doi.org/10.1016/j.marpolbul.2014.02.020

Schneider, U., 1993. Basstölpelbrutpaar auf dem Lummenfelsen. Seevögel 14, 24.

Secretariat of the Convention on Biological Diversity, 2012. Impacts of Marine Debris on Biodiversity: Current Status and Potential Solutions, CBD Technical Series. Secretariat of the Convention on Biological Diversity, Montreal.

Sergio, F., Blas, J., Blanco, G., Tanferna, A., López, L., Lemus, J.A., Hiraldo, F., 2011. Raptor Nest Decorations Are a Reliable Threat Against Conspecifics. Science 331, 327-330. https://doi.org/10.1126/science.1199422

Snow, B., 1960. The breeding biology of the shag Phalacrocorax aristotelis on the island of Lundy, Bristol Channel. Ibis 102, 554-575. https://doi.org/10.1111/j.1474-919X.1960.tb07132.x 
Tavares, D.C., da Costa, L.L., Rangel, D.F., de Moura, J.F., Zalmon, I.R., Siciliano, S., 2016. Nests of the brown booby (Sula leucogaster) as a potential indicator of tropical ocean pollution by marine debris. Ecological Indicators, Navigating Urban Complexity: Advancing Understanding of Urban Social - Ecological Systems for Transformation and Resilience 70, 10-14. https://doi.org/10.1016/j.ecolind.2016.06.005

Teuten, E.L., Saquing, J.M., Knappe, D.R.U., Barlaz, M.A., Jonsson, S., Björn, A., Rowland, S.J., Thompson, R.C., Galloway, T.S., Yamashita, R., Ochi, D., Watanuki, Y., Moore, C., Viet, P.H., Tana, T.S., Prudente, M., Boonyatumanond, R., Zakaria, M.P., Akkhavong, K., Ogata, Y., Hirai, H., Iwasa, S., Mizukawa, K., Hagino, Y., Imamura, A., Saha, M., Takada, H., 2009. Transport and release of chemicals from plastics to the environment and to wildlife. Philosophical Transactions of the Royal Society B: Biological Sciences 364, 2027-2045. https://doi.org/10.1098/rstb.2008.0284

Tinbergen, N., 1953. The herring gull's world: a study of the social behaviour of birds. Frederick A. Praeger, Inc., Oxford, England.

Verlis, K.M., Campbell, M.L., Wilson, S.P., 2014. Marine debris is selected as nesting material by the brown booby (Sula leucogaster) within the Swain Reefs, Great Barrier Reef, Australia. Marine Pollution Bulletin 87, 180-190. https://doi.org/10.1016/j.marpolbul.2014.07.060

Verner, J., 1961. Nesting activities of the red-footed booby in British Honduras. The Auk 78, 573594. https://doi.org/10.2307/4082191

Votier, S.C., Archibald, K., Morgan, G., Morgan, L., 2011. The use of plastic debris as nesting material by a colonial seabird and associated entanglement mortality. Marine Pollution Bulletin 62, 168-172. https://doi.org/10.1016/j.marpolbul.2010.11.009

Wilcox, C., Sebille, E.V., Hardesty, B.D., 2015. Threat of plastic pollution to seabirds is global, pervasive, and increasing. PNAS 112, 11899-11904. https://doi.org/10.1073/pnas.1502108112

Witteveen, M., Brown, M., Ryan, P.G., 2017. Anthropogenic debris in the nests of kelp gulls in South Africa. Marine Pollution Bulletin 114, 699-704. 